\title{
Changes in endotoxin levels in T2DM subjects on anti-diabetic therapies
}

\author{
Omar S Al-Attas*1, Nasser M Al-Daghri ${ }^{1}$, Khalid Al-Rubeaan ${ }^{2}$, Nancy F da \\ Silva $^{3}$, Shaun L Sabico ${ }^{1}$, Sudhesh Kumar ${ }^{3}$, Philip G McTernan ${ }^{3}$ and \\ Alison L Harte 3
}

Address: ${ }^{1}$ Biochemistry Department, College of Science King Saud University Riyadh, KSA, ${ }^{2}$ Diabetes Center, King Abdul-Aziz University Hospital, Riyadh, KSA and ${ }^{3}$ University of Warwick, Warwick Medical School, Diabetes and Metabolism Unit, Coventry, CV4 7AL, UK

Email: Omar S Al-Attas* - omrattas@ksu.edu.sa; Nasser M Al-Daghri - aldaghri2000@ hotmail.com; Khalid Al-Rubeaan - krubeaan@ksu.edu.sa; Nancy F da Silva - Nancy.FernandesDaSilva@astrazeneca.com; Shaun L Sabico - eaglescout01@yahoo.com;

Sudhesh Kumar - sudhesh.kumar@warwick.ac.uk; Philip G McTernan - p.g.mcternan@warwick.ac.uk; Alison L Harte - a.harte@warwick.ac.uk

* Corresponding author

Published: 15 April 2009

Cardiovascular Diabetology 2009, 8:20 doi:10.1 I86/1475-2840-8-20

This article is available from: http://www.cardiab.com/content/8/I/20

(c) 2009 Al-Attas et al; licensee BioMed Central Ltd.

This is an Open Access article distributed under the terms of the Creative Commons Attribution License (http://creativecommons.org/licenses/by/2.0), which permits unrestricted use, distribution, and reproduction in any medium, provided the original work is properly cited.

\begin{abstract}
Introduction: Chronic low-grade inflammation is a significant factor in the development of obesity associated diabetes. This is supported by recent studies suggesting endotoxin, derived from gut flora, may be key to the development of inflammation by stimulating the secretion of an adverse cytokine profile from adipose tissue.
\end{abstract}

Aims: The study investigated the relationship between endotoxin and various metabolic parameters of diabetic patients to determine if anti-diabetic therapies exerted a significant effect on endotoxin levels and adipocytokine profiles.

Methods: Fasting blood samples were collected from consenting Saudi Arabian patients (BMI: $30.2 \pm(\mathrm{SD}) 5.6 \mathrm{~kg} / \mathrm{m}^{2}, \mathrm{n}$ $=4 \mid 3)$, consisting of non-diabetics (ND: $n=67)$ and T2DM subjects $(n=346)$. The diabetics were divided into 5 subgroups based on their I year treatment regimes: diet-controlled $(n=36)$, metformin $(n=|4|)$, rosiglitazone (RSG: $n=22$ ), a combined fixed dose of metformin/rosiglitazone (met/RSG $n=100)$ and insulin $(n=47)$. Lipid profiles, fasting plasma glucose, insulin, adiponectin, resistin, TNF- $\alpha$, leptin, C-reactive protein (CRP) and endotoxin concentrations were determined.

Results: Regression analyses revealed significant correlations between endotoxin levels and triglycerides $\left(R^{2}=0.42 ; p<\right.$ $0.000 \mathrm{I})$; total cholesterol $\left(R^{2}=0.10 ; p<0.00 \mathrm{I}\right)$, glucose $\left(R^{2}=0.076 ; p<0.00 \mathrm{I}\right)$ and insulin $\left(R^{2}=0.032 ; p<0.00 \mathrm{I}\right)$ in T2DM subjects. Endotoxin showed a strong inverse correlation with HDL-cholesterol $\left(R^{2}=0.055 ; p<0.00 I\right)$. Further, endotoxin levels were elevated in all of the treated diabetic subgroups compared with ND, with the RSG treated diabetics showing significantly lower endotoxin levels than all of the other treatment groups (ND: $4.2 \pm 1.7 \mathrm{EU} / \mathrm{ml}$, RSG: $5.6 \pm 2.2 \mathrm{EU} / \mathrm{ml}$ ). Both the met/RSG and RSG treated groups had significantly higher adiponectin levels than all the other groups, with the RSG group expressing the highest levels overall.

Conclusion: We conclude that sub-clinical inflammation in T2DM may, in part, be mediated by circulating endotoxin. Furthermore, that whilst the endotoxin and adipocytokine profiles of diabetic patients treated with different therapies were comparable, the RSG group demonstrated significant differences in both adiponectin and endotoxin levels. We confirm an association between endotoxin and serum insulin and triglycerides and an inverse relationship with HDL. Lower endotoxin and higher adiponectin in the groups treated with RSG may be related and indicate another mechanism for the effect of RSG on insulin sensitivity. 


\section{Introduction}

In recent years, obesity, insulin resistance, as well as many of the features that comprise the metabolic syndrome, are associated with a low-grade, systemic, inflammatory condition $[1,2]$. In particular, the mediation of this sub-clinical inflammation in the pathogenesis of Type 2 Diabetes Mellitus (T2DM) is proposed to arise through increasing adiposity $[3,4]$; with adipose tissue representing a site of an acute phase response $[5,6]$ through the production of known pro-inflammatory adipocytokines such as leptin, tumor necrosis factor (TNF- $\alpha$ ) and interleukin (IL-6), amongst others [7-9]. Specifically, adipocytokines appear to have a duality of function, simultaneously mediating inflammation and insulin resistance through their effects on insulin action. Therefore, adipocytokines may function as a consequence of the cross-link proposed between metabolic and inflammatory pathways in adipocytes and immune cells [10-12].

Current therapies utilized in the treatment of T2DM include metformin and the thiazolidinediones (TZDs). These agents have principally been evaluated on the basis of their beneficial effects on glucose metabolism, due to their insulin enhancing properties. Metformin and rosiglitazone (RSG) are widely accepted first-line anti-diabetic drug therapies, whether taken as a monotherapy or in combination [13], and are considered effective with low incidence of hypoglycemia [14]. In addition to their effects on glucose homeostasis, metformin, itself, is known to reduce leptin, with resultant effects on inflammatory status and satiety [15]. Furthermore, the TZDs have previously been shown to have immunomodulatory effects [16]; reducing inflammation in both in-vitro and in-vivo models [17-19]. These findings highlight alternative pathways through which drug therapies are able to counteract the progressive nature of metabolic disease and their potential dual action on reducing obesity mediated T2DM.

Whilst metformin and the TZDs appear to offer dual functionality in insulin resistance and inflammation, the initial mediator for such an inflammatory insult is less well understood. One source of sub-clinical inflammation in patients with T2DM and coronary heart disease may arise through commensal bacteria derived from the gut, referred to as endotoxin [20]. Endotoxin is derived from lipopolysaccharide (LPS), which represents cell wall fragments of gram negative bacteria. Previous studies have demonstrated that subjects with obesity and T2DM have elevated circulating levels of endotoxin compared with non-diabetics (ND), which has been implicated in increased inflammatory risk [21]. Further support for this concept has arisen in subsequent studies where serum endotoxin levels are significantly higher in $o b / o b$ and $d b / d b$ mice compared with their normal weight counterparts [22]. Studies suggest elevated endotoxin levels may arise as a result of obesity related hyperinsulinemia; hence lowgrade endotoxinemia may be caused by the effect of insulin on intestinal motility and/or intestinal permeability. In support of this theory, murine studies analyzing the gastrointestinal tract (GIT) of $o b / o b$ and $d b / d b$ mice identified pathological changes in the GIT cells. The findings indicated that insulin may act directly on the GIT to affect gut permeability and potentially increase endotoxin absorption [22]. Elevated circulating levels of endotoxin may then initiate an inflammatory response within adipose tissue, via innate immunity, in conjunction with the liver, as the latter is the primary site of endotoxin clearance under normal physiological circumstances $[6,22]$. This mechanism may, therefore, explain the state of subclinical inflammation often present in obese and type 2 diabetic subjects [2].

Whilst limited data have been presented on the increase of endotoxin in pathological conditions such as obesity and diabetes, no data, as yet, have evaluated the influence of insulin sensitizers, in combination, on inflammatory risk posed by circulating endotoxin. Whilst there is a large quantity of data available on obesity and T2DM in relation to the Western world, less information exists regarding populations in the transitional state. In particular, Saudi Arabia has experienced a rapid increase in wealth over a relatively short period of time as a consequence of the financial gains rendered by the oil industry, paralleled with swift industrialization and urbanization [23]. As a result, the burden of disease in Saudi Arabia is high. The Obesity Taskforce worldwide projections for 2030 predict that the incidence of diabetes will rise by $32 \%$ in Europe, $72 \%$ in the USA but will increase by a massive $164 \%$ in the Middle East [24,25]. As such, it is clear we need to have a fundamental understanding of their risk of inflammation and how insulin sensitizers, along with other therapies, may reduce such a risk.

Therefore, the aims of this present study were to establish any associations between endotoxin and insulin, glucose, lipid profiles and pro-inflammatory cytokines in a Saudi Arabian cohort consisting of obese, ND subjects and obese, T2DM patients on various anti-diabetic therapies. Furthermore, the study aimed to examine the influence of diet, metformin, RSG, met/RSG as well as insulin on endotoxin levels and its' association with inflammation. Ultimately, this study will evaluate whether alterations in endotoxin, coupled with altered metabolic profile, in type 2 diabetics might further explain the observed improvement in the clinical profiles of patients treated with these therapies. This present study, in combination with our previous findings, may therefore help determine endotoxin as a novel biomarker of T2DM and diabetic risk and hence proffer a new target for the treatment or prevention of diabetes. 


\section{Methodology}

This single-centre, prospective and cross-sectional study was carried out at the Diabetes Center of King Abdul-aziz University Hospital in Riyadh, Kingdom of Saudi Arabia. The study protocol was approved by the institutional review board and was conducted in accordance with the guidelines set by the College of Medicine and Research Center of King Saud University, Riyadh, Kingdom of Saudi Arabia ethics committee. All patients submitted written and informed consent prior to inclusion.

\section{Subjects}

The study consisted of a total of 413 out-patients (male: 203; female: 210) age 20-80. Furthermore, 346 subjects were known type 2 diabetics, while the remaining 67 were $\mathrm{ND}$, closely matched for BMI.

Inclusion criteria for the diabetics (prior diagnosis) were determined in the first screening visit and included HBA1c 6-11\%, fasting plasma glucose 7.0-14.0 mmol/l; BMI $22-40 \mathrm{~kg} / \mathrm{m}^{2}$; without co-existing diabetic complications, i.e. diabetic retinopathy, nephropathy, etc. Subjects must have received treatment (diet controlled, metformin, RSG, met/RSG or insulin) for at least one year. ND subjects had normal fasting plasma glucose $(<5.6 \mathrm{mmol} / \mathrm{l})$; HBA1c levels (4-6\%) and were not taking any medications prior to commencement of research. Patients were excluded if they had poorly controlled diabetes with co-existing complications, smoking history, history of coronary heart disease and any unstable medical condition/s that would require immediate attention.

All subjects underwent a complete physical examination, which included an electrocardiogram prior to enrolment. Qualified patients were then stratified into 6 groups on the basis of their hypoglycemic therapies (diet-controlled $(\mathrm{n}=36)$, metformin $(\mathrm{n}=141)$, RSG $(\mathrm{n}=22)$, met/RSG ( $=100)$ and insulin $(\mathrm{n}=47))$, in addition to the ND group $(n=67)$. Following the findings of the initial study, a subgroup of diabetic subjects $\left(\mathrm{n}=11\right.$, BMI $\left.31.7 \pm 6.42 \mathrm{~kg} / \mathrm{m}^{2}\right)$ were treated with RSG for a period of 6 months (Post RSG: BMI $30.9 \pm 4.42 \mathrm{~kg} / \mathrm{m}^{2}$ ), in order to determine the specific effect of RSG treatment on endotoxin levels.

\section{In vivo Assessment of the Biochemical profile, Adipocytokines and Endotoxin Levels}

On the assigned date, fasting blood samples were collected from participating subjects and lipid profiles and fasting plasma glucose determined using routine laboratory methods. Adipocytokine levels were also assessed using various sandwich enzyme-linked immunosorbent assays (ELISAs). These included adiponectin (Linco Ltd, USA; intra-assay variability $7.0 \%$, interassay variability $8.4 \%$ ), resistin (RnD Systems Ltd, UK; intra- $4.0 \%$, interassay variability $7.7 \%$ ), TNF- $\alpha$ (RnD Systems Ltd, UK; intra- 5.2\%, interassay variability $7.4 \%$ ), leptin (intra$3.3 \%$, interassay variability $5.4 \%$ ) and C-reactive protein (CRP, Immunodiagnoztik AG, Germany; intra- 6\%, interassay variability $11.6 \%$ ). Insulin was analyzed via a solid phase enzyme amplified sensitivity immunoassay (Medgenix INS-ELISA, Biosource, Belgium). Lastly, endotoxin concentration was measured using a chromogenic kinetic limulus amebocyte assay (LAL assay, BioWhitaker, Walkersville MD), which had been validated, previously [21].

\section{Statistical Analyses}

Data were analyzed using the Statistical Package SPSS for Windows, version 11.5. Data were expressed as mean \pm standard deviation and mean (interquartile range) if not normally distributed. Groups were compared using ANOVA with Bonferroni adjustments for inter group comparisons. Simple and partial correlation coefficients between the variables were determined and multiple regression analysis was carried out to determine variables of interest. Triglycerides, insulin, leptin, adiponectin, CRP, resistin and endotoxin were logarithmically transformed to normalize data before correlations and statistical analyses were performed.

\section{Results \\ Metabolic and Clinical Characteristics}

Baseline characteristics

Table 1 shows the clinical and metabolic characteristics of the 6 groups analyzed in this study. The mean systolic blood pressures of the groups were similar, with the diet and RSG treated group having the lowest mean systolic blood pressures $(111.6 \pm 22.9 \mathrm{mmHg}$ and $114.1 \pm 28.7$ $\mathrm{mmHg}$, respectively) and the met/RSG group (128.4 \pm $23.6 \mathrm{mmHg}, \mathrm{p}<0.05)$ the highest. The mean diastolic blood pressures of the ND $(84.1 \pm 14.6 \mathrm{mmHg})$ and met/ RSG treated groups $(84.6 \pm 13.0 \mathrm{mmHg})$ were significantly lower than the insulin treated group $(96.0 \pm 15.5$ $\mathrm{mmHg}, \mathrm{p}<0.05$ ). Waist to hip ratios (WHR) were similar across all groups with the insulin treated group showing the highest WHR $(1.4 \pm 0.4)$, that differed significantly from the ND and the met/RSG treated groups (ND: $1.1 \pm$ 0.2; met/RSG: $1.1 \pm 0.3, \mathrm{p}<0.05)$. As would be expected, the ND group had significantly lower fasting plasma glucose levels compared with the other 5 groups. The groups were comparable in terms of lipid profile, although only the triglyceride levels in the diet and RSG treated groups (diet: 1.6(0.9-2.3) mmol/l; RSG: $1.6(0.8-2.3) \mathrm{mmol} / \mathrm{l}, \mathrm{p}$ $<0.05)$ did not differ significantly from the ND group (1.4(1.0-1.9) $\mathrm{mmol} / \mathrm{l}$, table 1$)$.

\section{Associations Between Endotoxin levels and Metabolic Factors in Subjects with T2DM}

Regression analyses revealed a significant correlation between endotoxin levels and triglycerides $\left(R^{2}=0.42 ; \mathrm{p}<\right.$ 
Table I: Clinical and Metabolic Characteristics of Subjects

\begin{tabular}{|c|c|c|c|c|c|c|}
\hline Variables & Non-Diabetic & Diet & Insulin & Metformin & Rosiglitazone & Met/RSG \\
\hline Age (years) & $44.1 \pm 9.9 \S \ddagger^{*}+* *$ & $48.3 \pm 9.1 \ddagger * * *$ & $55.6 \pm 11.4$ & $53.0 \pm 10.5$ & $52.3 \pm 9.5$ & $52.5 \pm 9.0$ \\
\hline BMI (kg/m²) & $30.0 \pm 5.2$ & $29.6 \pm 5.8$ & $29.0 \pm 6.2$ & $32.0 \pm 5.8$ & $29.6 \pm 5.8$ & $31.0 \pm 5.3$ \\
\hline Systolic (mmHg) & $117.3 \pm 20.0$ & $111.6 \pm 22.9 * * *$ & $115.7 \pm 24.9 * *$ & $123.8 \pm 23.5$ & $\mid 14.1 \pm 28.7^{* *}$ & $128.4 \pm 23.6$ \\
\hline Diastolic (mmHg) & $84.1 \pm 14.6 \ddagger^{*}$ & $88.2 \pm 14.9 \ddagger$ & $96.0 \pm 15.5^{* * * *}$ & $90.3 \pm 14.3^{* *}$ & $90.9 \pm 16.3$ & $84.6 \pm 13.0$ \\
\hline WHR & $1.1 \pm 0.2 \S \pm \dagger$ & $1.3 \pm 0.4^{* *}$ & $1.4 \pm 0.4 * *$ & $1.3 \pm 0.4^{* *}$ & $1.3 \pm 0.3 * *$ & $1.1 \pm 0.3$ \\
\hline Glucose (mmol/l) & $5.5 \pm 1.5 \S \ddagger^{*} \dagger^{* *}$ & $7.1 \pm 2.8 \ddagger^{* * * *}$ & $9.5 \pm 3.8$ & $9.6 \pm 3.4$ & $8.4 \pm 1.9$ & $9.4 \pm 3.9$ \\
\hline Insulin (ng/ml)\# & $20.1(10.9-23.0) \ddagger$ & $19.1(10.7-24.6) \ddagger$ & $29.9(21.2-36.6)^{* * *}$ & $20.7(10.9-27.3)$ & $21.5(11.8-20.5)$ & $17.1(7.6-17.2)$ \\
\hline LDL-C (mmol/l) & $3.2 \pm 0.9 \S^{*}$ & $2.7 \pm 0.8$ & $3.0 \pm 1.0$ & $2.8 \pm 0.8$ & $2.8 \pm 0.7$ & $3.0 \pm 1.4$ \\
\hline HDL-C (mmol/l) & $1.2 \pm 0.4$ & $1.3 \pm 0.7$ & $1.1 \pm 0.4$ & $\mathrm{I} . \mathrm{I} \pm 0.4$ & $1.0 \pm 0.4$ & $1.2 \pm 0.5$ \\
\hline TC (mmol/l) & $5.0 \pm 1.0$ & $4.7 \pm 1.0$ & $4.9 \pm 1.1$ & $4.8 \pm 1.0$ & $4.5 \pm 0.9 * *$ & $5.1 \pm 1.2$ \\
\hline TG (mmol/l)\# & $1.4(1.0-1.9)^{* * * *}$ & $1.6(0.9-2.3)^{* * *}$ & I.8(I.2-2.4) & $2.1(1.3-2.4)$ & $1.6(0.8-2.3)$ & $2.2(1.3-2.5)$ \\
\hline Leptin (ng/ml)\# & $31.0(14.6-42.2) \S^{*}+* *$ & $18.2(5.8-23.4) \ddagger$ & $27.5(9.8-39.3) \dagger^{* *}$ & $22.5(9.6-29.6)^{* *}$ & $16.2(5.2-19.8)$ & $18.6(4.9-21.7)$ \\
\hline Adiponectin $(\mu \mathrm{g} / \mathrm{ml}) \#$ & $8.5(5.1-1.0) \dagger^{* *}$ & $8.6(5.7-10.4) \dagger^{* *}$ & $10.4(5.3-13.2) \dagger^{* * *}$ & $9.1(6.0-11.3) \dagger^{* *}$ & $16.1(10.2-20.1)$ & $14.3(8.9-16.1)$ \\
\hline $\operatorname{CRP}(\mu \mathrm{g} / \mathrm{ml}) \#$ & $4.2(1.1-5.2)$ & $3.8(2.5-4.9) \ddagger$ & $6.3(1.5-6.5)^{* *}$ & $4.6(1.3-4.7)$ & $3.7(0.8-4.6)$ & $3.6(1.0-3.9)$ \\
\hline Resistin (ng/ml)\# & $15.6(10.7-19.8) \dagger$ & $15.0(14.5-17.9) \dagger$ & $17.6(10.5-18.4) \dagger^{* *}$ & $16.1(11.3-18.1) \dagger^{* *}$ & $11.9(8.0-13.7)^{* * *}$ & $14.2(10.4-16.7)$ \\
\hline TNF- $\alpha$ (pg/ml)\# & $5.4(3.4-7.3)^{* * *}$ & $4.7(2.9-6.2)$ & $5.4(2.7-7.4)^{*}$ & $4.2(2.8-5.3) \dagger$ & $5.9(4.3-6.8)^{* *}$ & $4.5(3.3-5.6)$ \\
\hline Endotoxin(EU/ml)\# & $4.2(3.1-5.1) \S \ddagger^{*} \dagger^{* * *}$ & $7.9(5.7-10.0) \dagger$ & $9.2(6.6-10.7)^{*}+* *$ & 7.5(4.6-8.7)† & $5.6(4.2-6.1)^{* *}$ & $7.4(4.8-9.6)$ \\
\hline
\end{tabular}

Clinical characteristics for non-diabetic (ND) and T2DM subjects on anti-diabetic therapies. Variables marked with \# were log transformed prior to statistical analysis. Hence data are presented as mean \pm SD unless log transformed (\#) in which case they are presented as mean (interquartile range). Significance was set at $p<0.05$. Therefore §denotes a significant difference in the mean values when compared with diet; $\ddagger$ denotes significance when compared with insulin; *denotes significance when compared with metformin; $\dagger$ denotes significance compared with RSG; ** denotes significance when compared with met/RSG.

0.0001, figure 1a); an inverse correlation between HDLcholesterol values $\left(\mathrm{R}^{2}=0.055 ; \mathrm{p}<0.001\right.$, figure $\left.1 \mathrm{~b}\right)$ and a significant correlation between total cholesterol levels $\left(\mathrm{R}^{2}\right.$ $=0.10 ; \mathrm{p}<0.001$, figure $1 \mathrm{c}$ ) in the diabetic cohort. The correlation between endotoxin levels and triglycerides, as well as cholesterol, remained even in the absence of diabetes $\left(\mathrm{R}^{2}=0.192 ; \mathrm{p}<0.0001\right.$, figure $2 \mathrm{a} ; \mathrm{R}^{2}=0.163 ; \mathrm{p}<$ 0.001 , figure $2 \mathrm{c}$ ). Lastly we found a significant association between endotoxin levels and insulin $\left(\mathrm{R}^{2}=0.032 ; \mathrm{p}<\right.$ 0.001 , figure $3 a)$ and glucose $\left(\mathrm{R}^{2}=0.076 ; \mathrm{p}<0.001\right.$, figure $3 \mathrm{~b})$ in the type 2 diabetics, which was not present in the
ND group (figure $3 c$ and $3 d$ ). The rest of the analyses were not significant.

Circulating Endotoxin Levels in ND and Treated T2DM Subjects Serum endotoxin levels were lowest in the ND group (4.2(3.1-5.1) EU/ml, table 1), with the insulin treated cohort exhibiting the highest levels (9.2(6.6-10.7) EU/ $\mathrm{ml}$, table 1$)$. Only the RSG treated group showed significantly lower endotoxin levels than all of the other antidiabetic therapies (RSG: 5.65(4.2-6.1) EU/ml, table 1). Compared with baseline values, endotoxin levels showed 

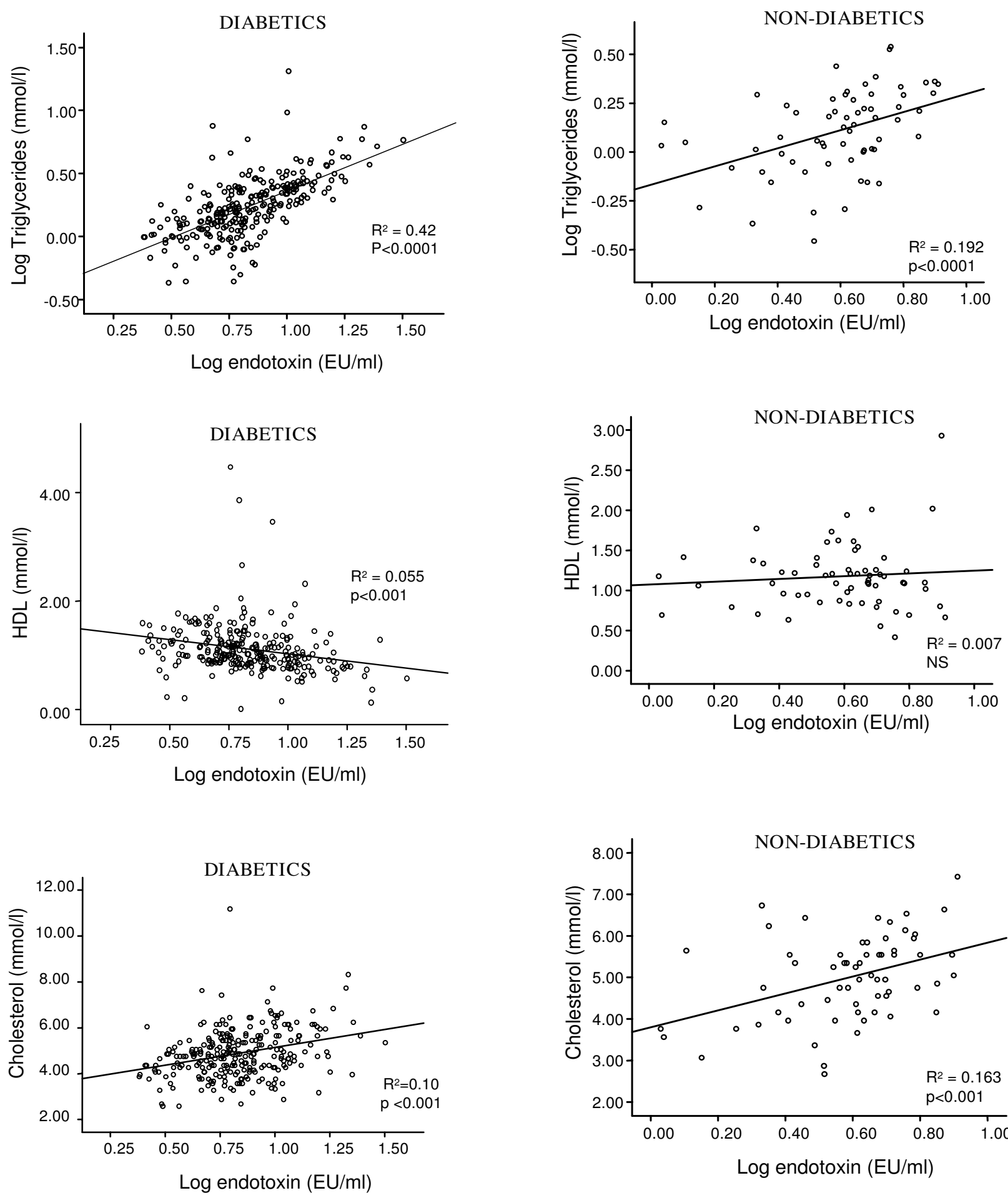

Figure I

Correlations between log fasting endotoxin (EU/ml) and a) log triglycerides (mmol/l), b) HDL ( $\mathrm{mmol} / \mathrm{l})$ and c) cholesterol ( $\mathrm{mmol} / \mathrm{l})$ in the whole diabetic cohort. The lines of best fit are also shown: a) $R^{2}=0.42, p<$ $0.000 \mathrm{I}$, b) $\mathrm{R}^{2}=0.055, \mathrm{p}<0.00 \mathrm{I}$, c) $\mathrm{R}^{2}=0.1, \mathrm{p}<0.00 \mathrm{I}$ ).

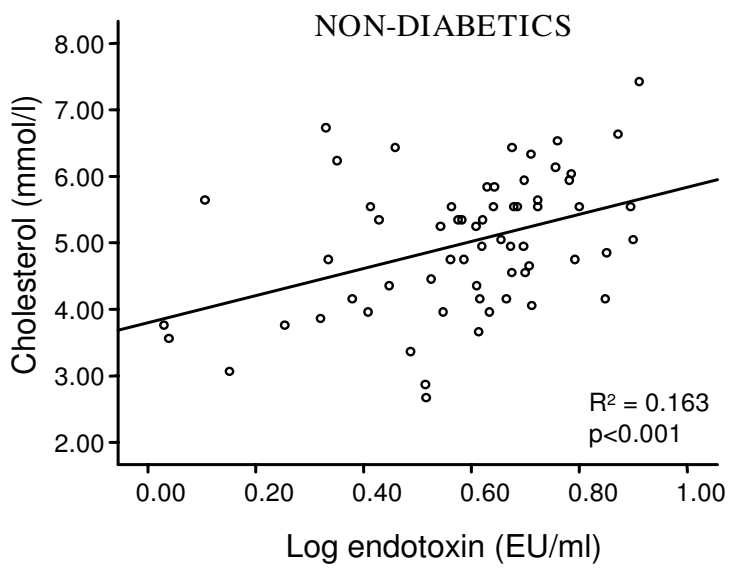

Figure 2

Correlations between log fasting endotoxin (EU/ml) and a) log triglycerides ( $\mathrm{mmol} / \mathrm{l})$, b) HDL ( $\mathrm{mmol} / \mathrm{l})$ and c) cholesterol ( $\mathrm{mmol} / \mathrm{l})$ in the non-diabetic (ND) group. The lines of best fit are also shown: a) $R^{2}=0.192, p<$ 0.000 I, b) $R^{2}=0.007$, not significant (NS); c) $R^{2}=0.163, p<$ $0.001)$. 


\section{DIABETICS}

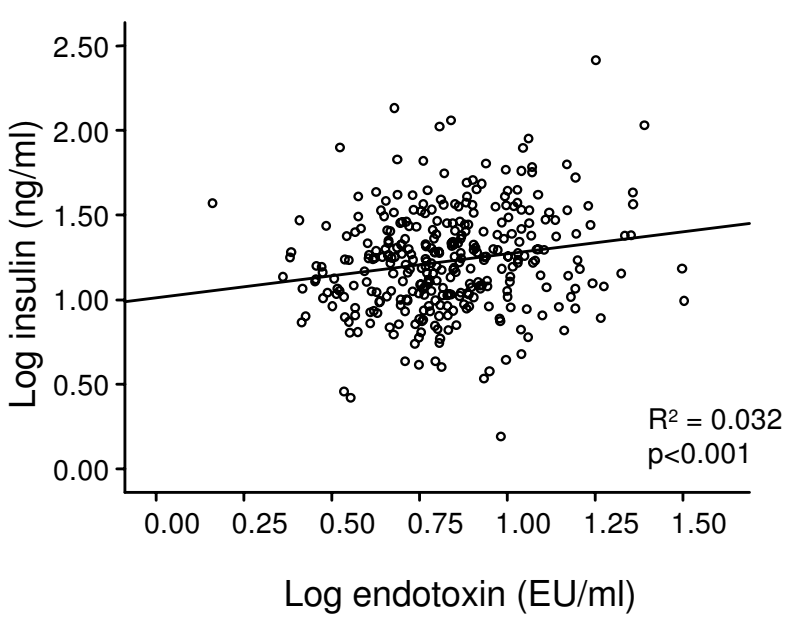

NON-DIABETICS

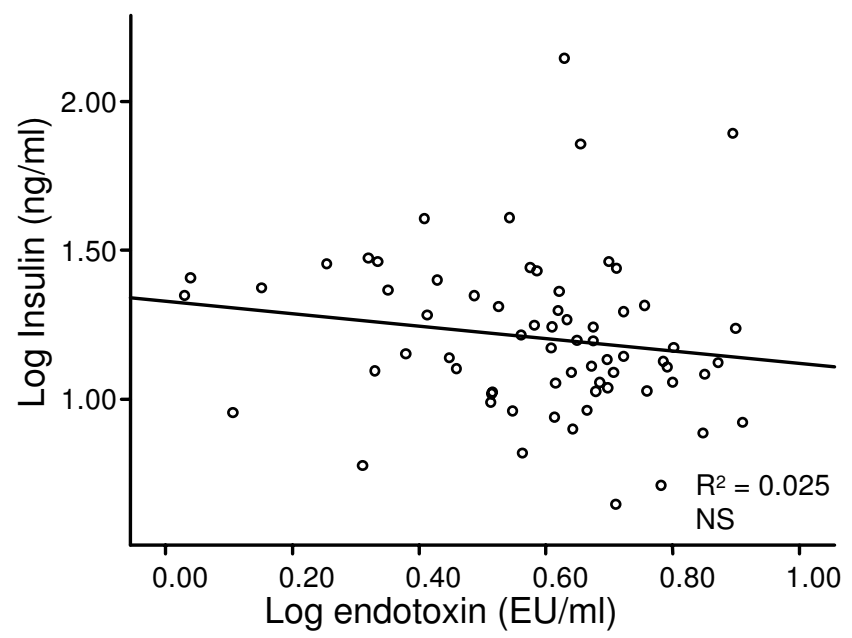

DIABETICS

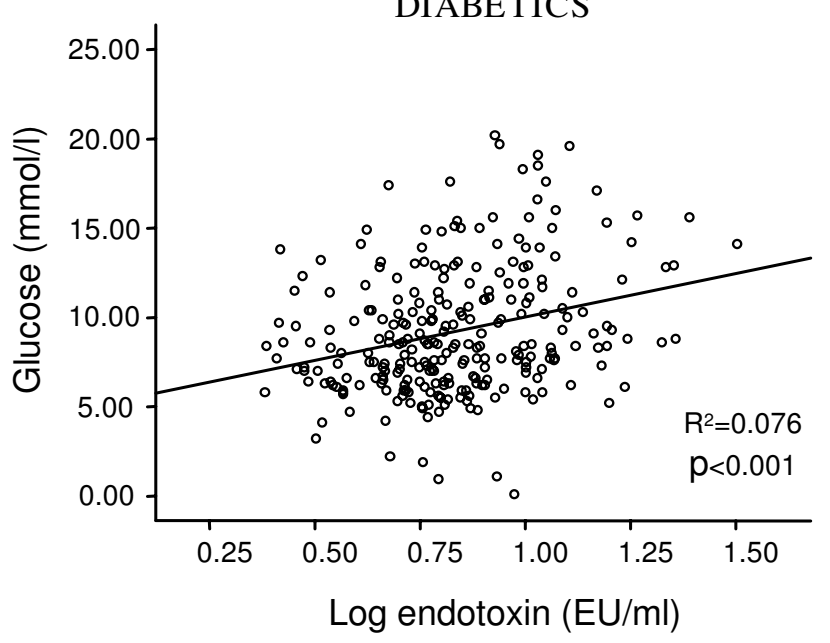

NON-DIABETICS

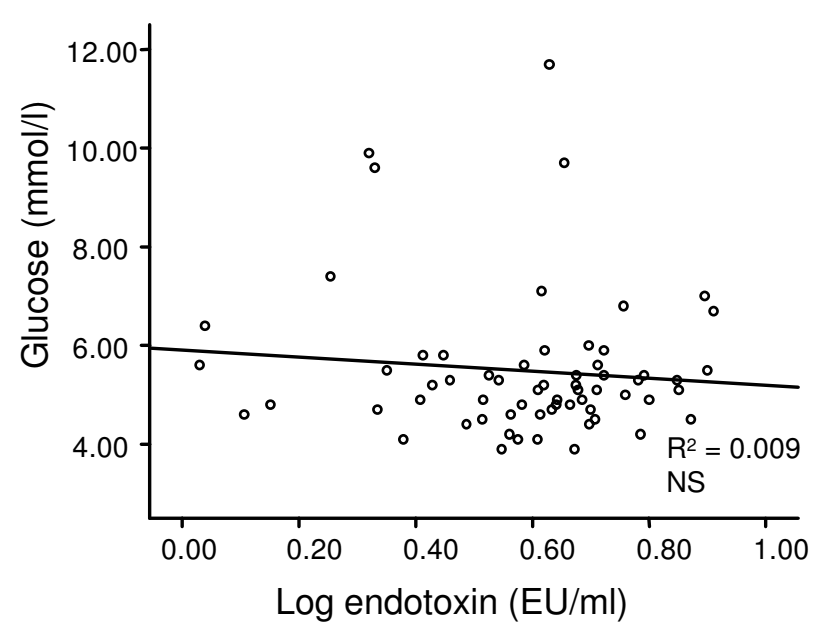

Figure 3

Correlations between log endotoxin (EU/ml) and a) log fasting insulin $(\mathrm{ng} / \mathrm{ml})$ and b) glucose $(\mathrm{mmol} / \mathrm{l})$ in the whole diabetic cohort. The lines of best fit are also shown: a) $R^{2}=0.032, p<0.00 I$, b) $R^{2}=0.076, p<0.00 \mathrm{I}$. Correlations between log endotoxin $(\mathrm{EU} / \mathrm{ml})$ and c) log fasting insulin $(\mathrm{ng} / \mathrm{ml})$ and $\mathrm{d})$ glucose $(\mathrm{mmol} / \mathrm{l})$ in the non-diabetic (ND) group. The lines of best fit are also shown: c) $\left.R^{2}=0.025, N S ; d\right) R^{2}=0.009$, NS.

a $13.5 \%$ decrease post treatment with RSG (Figure 4 , p < $0.05)$.

\section{Circulating Adipocytokine Levels}

With regard to adipocytokines, the leptin levels of the ND group (31.0(14.6-42.2) ng/ml) were significantly higher compared with the treated type 2 diabetic subgroups (table 1). Adiponectin levels in the RSG (16.1(10.2-20.1) $\mu \mathrm{g} / \mathrm{ml})$ and met/RSG $(14.3(8.9-16.1) \mu \mathrm{g} / \mathrm{ml})$ treated groups were significantly higher than all the other groups, with the RSG group showing almost a two fold increase in adiponectin levels compared with the ND (8.5(5.1-10.0) $\mu \mathrm{g} / \mathrm{ml}$, table 1$)$. The mean resistin levels of the groups were comparable, except for the RSG group which showed the lowest resistin levels overall (11.9(8.0-13.7)ng/ml, p $<0.05$, table 1). CRP levels were highest in the insulin 


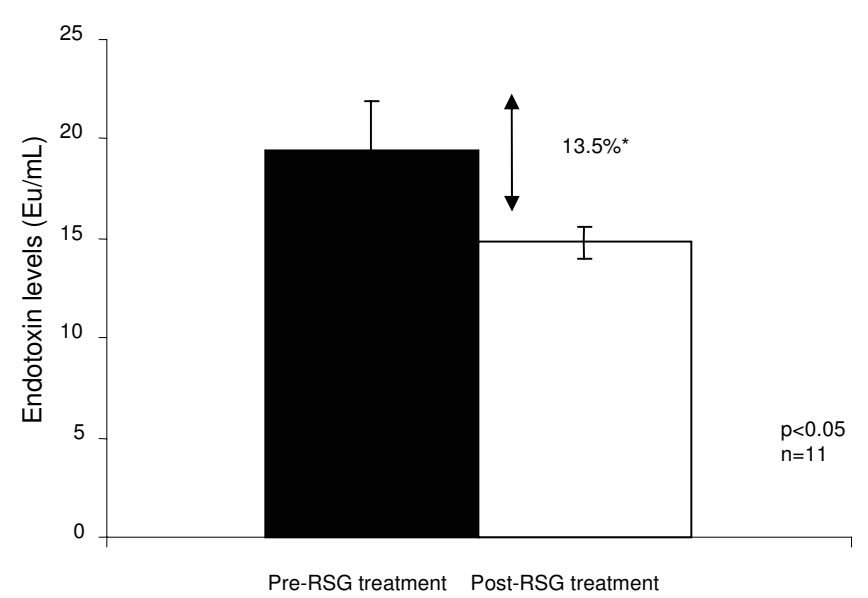

Figure 4

The mean levels of endotoxin (EU/ml) in sera from T2DM patients, pre and post RSG treatment $(n=I I$, p $<0.05 *)$

treated diabetics $(6.3(1.5-6.5) \mu \mathrm{g} / \mathrm{ml}, \mathrm{p}<0.05$, table 1$)$, whilst TNF- $\alpha$ levels were significantly higher in the RSG treated group (5.9(4.3-6.8) pg/ml, $\mathrm{p}<0.05$, table 1$)$.

\section{Discussion}

Recent studies have implicated a role for adipose tissue as a site of systemic inflammation, thus providing a direct link between obesity and the associated state of chronic sub-clinical inflammation [2]. One principal source for inflammatory risk may occur via the gastrointestinal tract (GIT), as previous studies have determined that endotoxin can activate the innate immune response within adipose tissue $[16,21,22,26,27]$. Such studies signify a potential role for gut flora related induction of innate immunity and circulating endotoxin in the pathogenesis of obesity induced T2DM.

The findings from this study have highlighted that subjects with T2DM had significantly elevated levels of endotoxin compared with BMI matched ND subjects. Hence, these studies have affirmed previous findings in Caucasian populations whilst increasing the studied subjects' numbers four fold [21]. Our findings also demonstrated that insulin treated subjects exhibited the highest circulating endotoxin levels of all the cohorts examined; additionally, both insulin and glucose were shown to correlate significantly with endotoxin levels in the diabetic cohort but not in the control group. As such, our current and previous data have highlighted an association between insulin and endotoxin, suggesting a mechanism that hyperinsulinemia/insulin resistance may lead to increased absorption of endotoxin through the GIT $[22,28]$. Whilst the findings of the present study support the endotoxin/gut absorption hypothesis, it has not deter- mined a causal effect and further studies would be required to examine this theory. Therefore, endotoxin may act as an inflammatory mediator in T2DM $[21,22]$. However our understanding of the relationship between glucose and endotoxin is less clear, as previous studies show no correlation between glucose levels and endotoxin [21], with Pederson and colleagues observing only a moderate increase in glucose levels when subjects underwent endotoxin infusion [29]. Conversely, severe human sepsis is known to instigate a hypermetabolic stress response, which includes hyperglycemia and impaired glucose tolerance [30]. Studies in T2DM patients have demonstrated that elevated glucose levels interfere with macrophage function, suppressing the bactericidal capacity of leukocytes [30], whilst murine studies have shown elevated glucose levels cause adverse effects on jejunum motility [31]. As such, hyperglycemia may make patients more susceptible to further infection - as observed in T2DM - as well as potentiating endotoxin absorption through inhibition of gut motility. Although patients with septic shock have considerably higher endotoxin levels (10 - 50 fold) than type 2 diabetics [32], subjects with cirrhosis are comparable with obese and T2DM subjects [33]. Therefore an association between glucose and endotoxin would suggest a role for endotoxin as an inflammatory mediator [34]. Our current findings have identified a clear, positive correlation between endotoxin and glucose serum levels [21]. The apparent discrepancies between our study and previous findings may have arisen due to the large size of the cohort we examined. Therefore the relationship between endotoxin and glucose should be investigated through subsequent studies to corroborate our findings.

The strong positive correlation identified between endotoxin and triglyceride levels is also of interest, noted in both the T2DM subjects and ND group. It is well established that subjects with obesity and T2DM have high serum triglyceride and low HDL $[35,36]$. Studies have indicated that HDL has a protective role against inflammation and the effects of endotoxin [37,38]. Low levels of HDL are associated with low levels of sCD14 [39], which corresponds with data showing that LPS binds to HDL in the presence of sCD14 and LPS binding protein (LBP) [40-42], and enzymes involved in the presentation of LPS to sCD14. This would imply that HDL is potentially involved in the immunological response to LPS. In contrast, serum triglyceride levels are directly stimulated by LPS [43] and are correlated with sCD14 [44]. Furthermore, it may act as a carrier of bacterial antigens and also facilitate their clearance $[45,46]$. These findings would have obvious implications in obese, T2DM patients.

Upon comparison of the different treatment regimes, only the RSG group showed circulating endotoxin levels signif- 
icantly lower than all of the other anti-diabetic therapies. The insulin treated cohort showed the highest circulating levels of endotoxin, which advocates the theory that insulin may promote increased endotoxin absorption from the GIT [22]. Furthermore, all of the cohorts on anti-diabetic drug treatments, metformin, RSG and met/RSG, showed significantly lower levels of endotoxin than insulin - with the RSG treated group exhibiting the most dramatic decrease. Upon further analysis of pre and post RSG treated T2DM subjects, there was a $13.5 \%$ decrease in endotoxin levels over a 6 month period. These results confirm previous studies to show that RSG significantly reduces endotoxin in T2DM patients [21], whilst also indicating that RSG has a more significant effect on endotoxin levels than other anti-diabetic therapies. Therefore, these findings may explain some of the anti-inflammatory properties of the TZDs.

In addition, RSG and met/RSG treated subjects both resulted in elevated adiponectin levels that, whilst comparable to one another, were significantly higher than all the other treated groups, including the ND group. These data affirm findings by Rosenstock and colleagues and support their suggestion that the observed increase in adiponectin is due to RSG, as the TZDs have been shown to consistently increase circulating adiponectin [47].

Assessment of other adipocytokines showed that leptin levels were highest amongst the ND group and did not correlate with endotoxin in all groups. However, to date, the findings regarding leptin are conflicting. Patients with sepsis are known to have elevated levels of leptin [48], yet several studies have failed to demonstrate an increase in leptin with endotoxin infusion $[49,50]$, whilst studies in mice and hamsters show increased leptin at the serum and mRNA level with endotoxin administration [51,52]. Such differences may have arisen from methodological reasons, as our study measured the relationship between leptin and endogenous endotoxin serum levels, as opposed to the effects on leptin as a result of exogenous endotoxin administration. Furthermore, within this study, the diabetic drugs may have decreased leptin concentration, altering the determined findings $[15,53]$.

In summary, both ND and diabetic subjects showed significant associations with endotoxin and triglycerides and total cholesterol. T2DM subjects demonstrated an inverse correlation between endotoxin and HDL-cholesterol and positive correlations between endotoxin and glucose and endotoxin and insulin. As such, endotoxin may mediate various metabolic changes in people with T2DM in response to an increasing insulin resistant state, which is also consistent with chronic systemic low-grade inflammation. Our data suggest that the sub-clinical inflammation observed in T2DM patients may, in part, be derived from commensal bacteria [54]. Whilst clinical treatment of T2DM implies that RSG has the most favorable effect on overall endotoxin reduction and adipocytokine profiles in the T2DM patients, the present studies have simply identified associations and clearly additional randomized studies are required to determine the cause and effect via further examination of the role of endotoxin and the insulin resistant state. However current data suggest that endotoxin may represent an important mediator for inflammatory related metabolic risk.

\section{Competing interests}

The authors declare that they have no competing interests.

\section{Authors' contributions}

OA for the design, statistical analysis and drafting of the manuscript; NA for the drafting and revising of the manuscript; KA for the acquisition and interpretation of data; NdS for performing the endotoxin assays; SS for the statistical analysis and interpretation of data; PM and SK for the concept, interpretation of data and intellectual input; $\mathrm{AH}$ for the design and concept, manuscript development and final revision of the paper.

\section{Acknowledgements}

The authors are grateful to staff at the Diabetes Center, King Abdul-Aziz University Hospital for the sample collection and Mr. Ahmed A.

Bamakramah for the sample analysis and technical assistance. We would also like to thank the British Medical Association for providing funds to carry out these studies, as well as the Arden Medical Research Fund and the British Heart Foundation for supporting a fellowship for Dr Alison Harte.

\section{References}

I. Dandona P, Aljada A, Bandyopadhyay A: Inflammation: the link between insulin resistance, obesity and diabetes. Trends Immunol 2004, 25:4-7.

2. Wellen KE, Hotamisligil GS: Inflammation, stress, and diabetes. J Clin Invest 2005, I I 5: I I I I-I I I9.

3. Deeg MA: Basic approach to managing hyperglycemia for the nonendocrinologist. Am J Cardiol 2005, 96:37E-40E.

4. Sheehan MT: Current therapeutic options in type 2 diabetes mellitus: a practical approach. Clin Med Res 2003, I: 189-200.

5. Calabro P, Yeh ET: Obesity, inflammation, and vascular disease: the role of the adipose tissue as an endocrine organ. Subcell Biochem 2007, 42:63-91.

6. Brix-Christensen V, Vestergaard C, Andersen SK, Krog J, Andersen NT, Larsson A, Schmitz O, Tonnesen E: Evidence that acute hyperinsulinaemia increases the cytokine content in essential organs after an endotoxin challenge in a porcine model. Acta Anaesthesiol Scand 2005, 49:|429-|435.

7. Arkan MC, Hevener AL, Greten FR, Maeda S, Li ZW, Long JM, Wynshaw-Boris A, Poli G, Olefsky J, Karin M: IKK-beta links inflammation to obesity-induced insulin resistance. Nat Med 2005, I I:191-198.

8. Trayhurn P, Wood IS: Adipokines: inflammation and the pleiotropic role of white adipose tissue. Br J Nutr 2004, 92:347-355.

9. Trayhurn P, Wood IS: Signalling role of adipose tissue: adipokines and inflammation in obesity. Biochem Soc Trans 2005, 33:1078-108I.

10. Kusminski CM, da Silva NF, Creely SJ, Fisher FM, Harte AL, Baker AR, Kumar S, McTernan PG: The in vitro effects of resistin on the innate immune signaling pathway in isolated human subcutaneous adipocytes. J Clin Endocrinol Metab 2007, 92:270-276. 
II. Weisberg SP, McCann D, Desai M, Rosenbaum M, Leibel RL, Ferrante AW Jr: Obesity is associated with macrophage accumulation in adipose tissue. J Clin Invest 2003, I I 2: I 796-1808.

12. Xu H, Barnes GT, Yang Q, Tan G, Yang D, Chou CJ, Sole J, Nichols A, Ross JS, Tartaglia LA, Chen H: Chronic inflammation in fat plays a crucial role in the development of obesity-related insulin resistance. J Clin Invest 2003, I I 2: | 82 | - | 830.

13. Stewart MW, Cirkel DT, Furuseth K, Donaldson J, Biswas N, Starkie MG, Phenekos C, Hamann A: Effect of metformin plus roziglitazone compared with metformin alone on glycaemic control in well-controlled Type $\mathbf{2}$ diabetes. Diabet Med 2006, 23:1069-1078

14. Weissman P, Goldstein BJ, Rosenstock J, Waterhouse B, Cobitz AR, Wooddell MJ, Strow LJ: Effects of rosiglitazone added to submaximal doses of metformin compared with dose escalation of metformin in type 2 diabetes: the EMPIRE Study. Curr Med Res Opin 2005, 2 I:2029-2035.

15. Kim YW, Kim JY, Park YH, Park SY, Won KC, Choi KH, Huh JY Moon $\mathrm{KH}$ : Metformin restores leptin sensitivity in high-fat-fed obese rats with leptin resistance. Diabetes 2006, 55:716-724.

16. Chinetti G, Fruchart JC, Staels B: Peroxisome proliferator-activated receptors (PPARs): nuclear receptors at the crossroads between lipid metabolism and inflammation. Inflamm Res 2000, 49:497-505.

17. Buckingham RE: Thiazolidinediones: Pleiotropic drugs with potent anti-inflammatory properties for tissue protection. Hepatol Res 2005, 33:167-170.

18. Murdolo G, Smith U: The dysregulated adipose tissue: a connecting link between insulin resistance, type 2 diabetes mellitus and atherosclerosis. Nutr Metab Cardiovasc Dis 2006, I 6(Suppl I):S35-38.

19. van Doorn $M$, Kemme $M$, Ouwens $M$, van Hoogdalem EJ, Jones $R$, Romijn H, de Kam M, Schoemaker R, Burggraaf K, Cohen A: Evaluation of proinflammatory cytokines and inflammation markers as biomarkers for the action of thiazolidinediones in Type 2 diabetes mellitus patients and healthy volunteers. $\mathrm{Br}$ J Clin Pharmacol 2006, 62:39|-402.

20. Charalambous BM, Stephens RC, Feavers IM, Montgomery HE: Role of Bacterial Endotoxin in Chronic Heart Failure: the Gut of the Matter. Shock 2007, 28:15-23.

21. Creely SJ, McTernan PG, Kusminski CM, Fisher M, Da Silva NF, Khanolkar M, Evans M, Harte AL, Kumar S: Lipopolysaccharide activates an innate immune system response in human adipose tissue in obesity and type 2 diabetes. Am J Physiol Endocrinol Metab 2007, 292:E740-747.

22. Brun P, Castagliuolo I, Leo VD, Buda A, Pinzani M, Palu G, Martines $D$ : Increased intestinal permeability in obese mice: new evidence in the pathogenesis of nonalcoholic steatohepatitis. Am J Physiol Gastrointest Liver Physiol 2007, 292:G5 I8-525.

23. Galal O: Nutrition-related health patterns in the Middle East. Asia Pac J Clin Nutr 2003, I 2:337-343.

24. Hossain P, Kawar B, El Nahas M: Obesity and diabetes in the developing world - a growing challenge. N Engl J Med 2007, 356:2I3-2I5.

25. Wild S, Roglic G, Green A, Sicree R, King H: Global prevalence of diabetes: estimates for the year 2000 and projections for 2030. Diabetes Care 2004, 27:1047-1053.

26. Cani PD, Amar J, Iglesias MA, Poggi M, Knauf C, Bastelica D, Neyrinck AM, Fava F, Tuohy KM, Chabo C, et al.: Metabolic endotoxemia initiates obesity and insulin resistance. Diabetes 2007, 56: $176 \mid-1772$

27. Backhed F, Manchester JK, Semenkovich CF, Gordon Jl: Mechanisms underlying the resistance to diet-induced obesity in germ-free mice. Proc Natl Acad Sci USA 2007, 104:979-984.

28. Westergaard $\mathrm{H}$ : Insulin modulates rat intestinal glucose transport: effect of hypoinsulinemia and hyperinsulinemia. $A m$ J Physiol 1989, 256:G91।-918.

29. Krogh-Madsen R, Moller K, Dela F, Kronborg G, Jauffred S, Pedersen $B K$ : Effect of hyperglycemia and hyperinsulinemia on the response of IL-6, TNF-alpha, and FFAs to low-dose endotoxemia in humans. Am J Physiol Endocrinol Metab 2004, 286:E766-772.

30. Yu WK, Li WQ, Li N, Li JS: Influence of acute hyperglycemia in human sepsis on inflammatory cytokine and counterregulatory hormone concentrations. World J Gastroenterol 2003. 9:1824-1827.
3I. Byrne MM, Pluntke K, Wank U, Schirra J, Arnold R, Goke B, Katschinski $M$ : Inhibitory effects of hyperglycaemia on fed jejunal motility: potential role of hyperinsulinaemia. Eur J Clin Invest 1998, 28:72-78.

32. Cohen J: The detection and interpretation of endotoxaemia. Intensive Care Med 2000, 26(SuppI I):S5I-56.

33. Guarner C, Soriano G, Tomas A, Bulbena O, Novella MT, Balanzo J Vilardell F, Mourelle M, Moncada S: Increased serum nitrite and nitrate levels in patients with cirrhosis: relationship to endotoxemia. Hepatology 1993, I 8: I|39-I| 43.

34. Mitaka C: Clinical laboratory differentiation of infectious versus non-infectious systemic inflammatory response syndrome. Clin Chim Acta 2005, 35 I: I7-29.

35. Kannel WB: Lipids, diabetes, and coronary heart disease: insights from the Framingham Study. Am Heart J 1985, I I0: I 100-1 I07.

36. Laakso M, Pyorala K: Adverse effects of obesity on lipid and lipoprotein levels in insulin-dependent and non-insulindependent diabetes. Metabolism 1990, 39: I I7-I22.

37. Hudgins LC, Parker TS, Levine DM, Gordon BR, Saal SD, Jiang XC Seidman CE, Tremaroli JD, Lai J, Rubin AL: A single intravenous dose of endotoxin rapidly alters serum lipoproteins and lipid transfer proteins in normal volunteers. I Lipid Res 2003, 44:|489-| 498.

38. Levine DM, Parker TS, Donnelly TM, Walsh A, Rubin AL: In vivo protection against endotoxin by plasma high density lipoprotein. Proc Natl Acad Sci USA 1993, 90: I 2040- I 2044

39. Eggesbo JB, Hjermann I, Lund PK, Joo GB, Ovstebo R, Kierulf P: LPSinduced release of IL-I beta, IL-6, IL-8, TNF-alpha and sCD I 4 in whole blood and PBMC from persons with high or low levels of HDL-lipoprotein. Cytokine 1994, 6:52 I-529.

40. Parker TS, Levine DM, Chang JC, Laxer J, Coffin CC, Rubin AL: Reconstituted high-density lipoprotein neutralizes gramnegative bacterial lipopolysaccharides in human whole blood. Infect Immun 1995, 63:253-258.

41. Wurfel MM, Hailman E, Wright SD: Soluble CDI4 acts as a shuttle in the neutralization of lipopolysaccharide (LPS) by LPSbinding protein and reconstituted high density lipoprotein. J Exp Med 1995, I 8 I: I 743-1754

42. Wurfel MM, Kunitake ST, Lichenstein $H$, Kane JP, Wright SD: Lipopolysaccharide (LPS)-binding protein is carried on lipoproteins and acts as a cofactor in the neutralization of LPS. J Exp Med 1994, 180:1025-1035

43. Feingold KR, Staprans I, Memon RA, Moser AH, Shigenaga JK, Doerrler W, Dinarello CA, Grunfeld C: Endotoxin rapidly induces changes in lipid metabolism that produce hypertriglyceridemia: low doses stimulate hepatic triglyceride production while high doses inhibit clearance. I Lipid Res 1992 , 33:1765-1776.

44. Fernandez-Real JM, Broch M, Richart C, Vendrell J, Lopez-Bermejo A, Ricart W: CDI 4 monocyte receptor, involved in the inflammatory cascade, and insulin sensitivity. J Clin Endocrinol Metab 2003, 88: $1780-1784$

45. Eichbaum EB, Harris HW, Kane JP, Rapp JH: Chylomicrons can inhibit endotoxin activity in vitro. J Surg Res I991, 5 I:4I3-4I6.

46. Harris HW, Grunfeld C, Feingold KR, Read TE, Kane JP, Jones AL, Eichbaum EB, Bland GF, Rapp JH: Chylomicrons alter the fate of endotoxin, decreasing tumor necrosis factor release and preventing death. J Clin Invest 1993, 91:1028-1034.

47. Rosenstock J, Rood J, Cobitz A, Biswas N, Chou H, Garber A: Initial treatment with rosiglitazone/metformin fixed-dose combination therapy compared with monotherapy with either rosiglitazone or metformin in patients with uncontrolled type 2 diabetes. Diabetes Obes Metab 2006, 8:650-660.

48. Bornstein SR, Licinio J, Tauchnitz R, Engelmann L, Negrao AB, Gold $P$, Chrousos GP: Plasma leptin levels are increased in survivors of acute sepsis: associated loss of diurnal rhythm, in cortisol and leptin secretion. J Clin Endocrinol Metab 1998, 83:280-283.

49. Bornstein SR, Preas HL, Chrousos GP, Suffredini AF: Circulating leptin levels during acute experimental endotoxemia and antiinflammatory therapy in humans. J Infect Dis 1998, | 78:887-890.

50. Granowitz EV, Porat R, Dinarello CA: Circulating leptin during experimental endotoxemia in humans. J Infect Dis 1999, 179:1313-13|4 
5I. Berkowitz DE, Brown D, Lee KM, Emala C, Palmer D, An Y, Breslow $M$ : Endotoxin-induced alteration in the expression of leptin and beta3-adrenergic receptor in adipose tissue. Am J Physiol 1998, 274:E992-997.

52. Grunfeld C, Zhao C, Fuller J, Pollack A, Moser A, Friedman J, Feingold $K R$ : Endotoxin and cytokines induce expression of leptin, the ob gene product, in hamsters. J Clin Invest 1996, 97:2152-2157.

53. Wu ], Lei MX, Chen HL, Sun ZX: [Effects of rosiglitazone on serum leptin and insulin resistance in patients with Type 2 diabetes]. Zhong Nan Da Xue Xue Bao Yi Xue Ban 2004, 29:623-626.

54. Lu H, Raptis M, Black E, Stan M, Amar S, Graves DT: Influence of diabetes on the exacerbation of an inflammatory response in cardiovascular tissue. Endocrinology 2004, 145:4934-4939.

Publish with Bio Med Central and every scientist can read your work free of charge

"BioMed Central will be the most significant development for disseminating the results of biomedical research in our lifetime. "

Sir Paul Nurse, Cancer Research UK

Your research papers will be:

- available free of charge to the entire biomedical community

- peer reviewed and published immediately upon acceptance

- cited in PubMed and archived on PubMed Central

- yours - you keep the copyright

Submit your manuscript here:

http://www.biomedcentral.com/info/publishing_adv.asp
BioMedcentral 